\title{
Break Even Analysis
}

\section{Thomas E Catanzaro*}

American College of Healthcare Executives, CEO, Veterinary Consulting International, Australia

${ }^{*}$ Corresponding author: Catanzaro TE, American College of Healthcare Executives, CEO, Veterinary Consulting International, Australia, Tel: +610416285975; E-mail: DrTomCat@aol.com

Received date: Mar 04, 2016, Accepted date: May 24, 2016, Published date: May 27, 2016

Copyright: (C) 2016 Catanzaro TE. This is an open-access article distributed under the terms of the Creative Commons Attribution License, which permits unrestricted use, distribution, and reproduction in any medium, provided the original author and source are credited.

\section{Introduction}

As stated in the AAHA primer text, Successful Financial Management for the Veterinary Practice, there is an entire body of accounting and financial theory which deals with cost analysis and accounting of those costs. This same reference explains Cost Behavior Patterns, Break-Even Analysis, and Cost-Volume-Profit Analysis in Chapter 3 and some useful veterinary financial ratios in Chapter 5, so I will not reiterate those facts or factors. It is also assumed that the annual cash budget is being effectively planned, as discussed in Chapter 4 of the above mentioned text. It is my belief that a practice must clearly identify fixed and variable costs before it attempts fiscal analysis of cost data by any of the above mentioned methods.

\section{Simple Dr. Tom Cat Shockers}

CODS-single digits (cost of drugs sold is a good management tool since it is not an accountant's combination of all medical costs - CMS).

Staff as \% of Gross - in a team based practice, all W-2 compensation costs are combined, doctors and staff alike, and need to be less than $43 \%$. Specialty hospitals can be a bit higher, while Australian and New Zealand Practices need to be below 39\%. If the owner is not on a percentage of production and only uses an arbitrary draw, that draw can be allocated as $25 \% \mathrm{~W}-2$ and the balance ROI.

Nutrition - profit should be between $35-40 \%$ of sales in USA, $10 \%$ lower in Australia or New Zealand.

Pharmacy Sales - usually double any purchase costs, unless there is a price war going on in the catchment area. In reality, inventory has a major overhead seldom tracked, including staff costs for inventory management and expired products.

Lab income to Lab expense - the difference between using a referral lab and doing it in-house lies in manpower costs, reagent costs, and turn-around time. If doing the minimum for a desex (neuter), PCV, TP, and BUN is adequate (per VIN boards - cost $\sim \$ 6$ unless you are using Azo sticks, then it is less than $\$ 2$ cost) - inexpensive and an in-house STAT procedure.

Hope you are beginning to see the operational relationships. TC

\section{Cost Centers and Profit Centers}

Practice managers usually analyze costs on a specific element of expense, but often the expense code used does not have an equal income source identified for analysis purposes. A good Chart of Accounts will ensure that each of the cost centers (expense item) are calibrated to the corresponding income centers (invoice category) for effective profit analysis. A healthy practice can maintain expenses to about 45-48 percent of the monthly gross (if rent, all veterinarian monies, and ROI factors are backed out of the expenses before computation). The costs in most well run practices are usually within control in today's environment, so the real concern is to maximize income centers. This means that segregation and subsequent analysis of fixed and variable expenses should look at costs in three basic perspectives:

- The relationship between costs, patient volume, and net income should be more readily accessible.

- Fixed and variable cost analysis would help the practice manager determine which costs could be reduced and which costs could be eliminated.

- Segregating costs is a prerequisite for using more sophisticated methods of cost analysis, such as the break-even analysis and other cost, profit, and volume analysis.

Profit center management is simply the term used to mean aligning the income sources to the associated expenses, then comparing the two sets of figures for trends (and hopefully net income). Some consultants advocate the computation of floor space committed to an income center, and divide the circulating spaces (hallways/offices/rest rooms) into "fair shares" for each income area. This is not a rational approach for a progressive veterinary practice that deals in total patient wellness, which offers service as it is needed by the patient. It is arbitrary and confuses the use of specific diagnostic areas that support the other income areas of the practice with a floor plan that is out-of-date or in need of system assessment for improvement.

\section{Identifying Fixed and Variable Costs}

The typical veterinary practice must be ready for virtually any animal health care emergency at any time. Surgery, radiology, and ancillary support functions are demands that must be ready at all times of operation. To a great extent, salaries, utilities, and other costs incurred to maintain this standby status are not directly related to the number of patients/clients seen. Without a direct relationship between patient volume and practice costs, fixed and variable costs cannot be readily defined. With the help of your accountant, all costs can be broken into four categories:

- Committed Fixed Costs

- Discretionary Fixed Costs

- Pure Variable Costs

- Step Variable Costs

Each category will be defined and discussed, but the elements of expense must be evaluated line item by line item to see which category of cost each element should be assigned. An example of laboratory costs is provided at the bottom of the chart, but this process should be done for each area of concern. 


\section{Committed Fixed Costs}

Committed fixed costs are the initial and ongoing costs which are essential to the basic practice of veterinary medicine; the costs associated with being ready to receive clients and treat patients. Committed costs include: interests on debt, depreciation of assets, management salaries, insurance, lease of plant and equipment, audit fees, taxes, rent, and other costs that do not vary with the volume but which will be incurred as long as the practice serves the community. These costs cannot be eliminated, but they may be minimized by thorough analysis prior to commitment (Table 1).

\begin{tabular}{|l|l|l|l|l|}
\hline \multicolumn{2}{|l|}{ Fixed costs } & \multicolumn{2}{l|}{ Variable costs } \\
\hline Element of expense & Committed & Discretionary & Pure & Step \\
\hline Management Salaries & $\$ X X$ & & & $\$ X X$ \\
\hline Other Salaries & & & & \\
\hline Rent & $\$ X X$ & & & \\
\hline Medical Supplies & & & $\$ X X$ & \\
\hline Non-medical Supplies & & & $\$ X X$ & \\
\hline Office Supplies & & & & $\$ X X$ \\
\hline Minor Equipment & & & & $\$ X X$ \\
\hline Telephone & $\$ X X+$ & $\$ X X$ & & \\
\hline Outside Services & & & $\$ X X$ & \\
\hline Equipment Repair & & & & $\$ X X$ \\
\hline Lease Expense & $\$ X X$ & & & \\
\hline Maintenance Contract & & & & $\$ X X$ \\
\hline CE Expenses & & $\$ X X$ & & \\
\hline Taxes & $\$ X X$ & & $\$ X X+$ & $\$ X X$ \\
\hline Total Lab Expense $=$ & $\$ X X+$ & $\$ X X+$ & & \\
\hline
\end{tabular}

Table 1: Committed fixed costs.

\section{Discretionary Fixed Costs}

Discretionary fixed costs are incurred because management decides that certain programs are needed or desirable. These are generally seen as non-patient care programs. Discretionary costs include: community and public relation programs, management development programs, travel budgets, charity services to patients, employee picnics, consultant fees, internal auditing, and other costs that are generally incurred on an annual basis. During the budgeting process, discretionary costs can often be severely cut without affecting the care of patients.

\section{Pure Variable Costs}

Pure variable costs vary proportionately to some unit of output. These would include such items as: medical supplies, drugs, and food used for treatment of patients (direct materials); nonmedical supplies such as laundry expenses, data processing costs, admission and billing forms which vary directly with changes in the inpatient numbers (indirect supplies); and certain purchased services. Labor costs cannot be included since they do not vary proportionately to the changes in case load. Since most of the pure variable costs are materials, inventory control procedures become important tools to control these costs. A system must be in place to insure that every client is charged for all materials used in the treatment of the patient.

\section{Step Variable Costs}

The greatest portion of practice variable costs are step variable costs. These costs increase or decrease only because of larger changes in patient/client numbers. These costs include: direct and indirect labor costs, employee fringe benefits, utilities, office and housekeeping supplies, and purchased services, such as maintenance contracts. These costs can be adjusted more readily than fixed costs, but is often not done for loyalty to staff reasons. Some techniques that may be used to control step variable costs include:

1. Schedule vacations during those slow months so that full staff is available in the busy months.

2. Look to temporary or part-time hires to extend the labor pool available to the practice as the season dictates.

3. Cross-train various individuals to perform several duties, such as technicians backing up receptionists at the end-of-day rush at the front desk, and using high school kids at minimum wage to do the clean up the technicians have been tasked to perform in the back at the close of business daily.

4. Insure that the veterinarians do only professional duties and lower paid staff are used for clerical, maintenance, and other nonprofessional duties.

5. Establish a part-time "on call" pool of trained support staff (such as extra receptionists) who will extend the staff at key times without causing great increases in payroll and benefit packages.

\section{Other Uses of Fixed and Variable Cost Data}

The cash budget process briefly discussed and illustrated in Chapter 4 of the AAHA text Successful Financial Management, presumes many things, such as an adequate practice accounting system. After visiting over 800 veterinary facilities in the last five years, I can tell you that most practices do not have good income center accounting, and try to be successful by managing expenses. Some of this approach lies with the MBA or CPA mentality advising the practice; tracking expenses is far "safer" for an adviser than assessing income sources. With an inflation rate like we have, controlling expenses is not the road to success. Expenses are only the road signs for the income producing services that a practice offers to the clients and for the patients.

These break-even analysis and fiscal management suggestions are the initial steps to good cost control using fixed and variable costs. Once the practice's elements of expense have been classified by management, they can be addressed in daily operational decisions. The scope of evaluation can be expanded as the data becomes more valid, such as:

- Looking at profitability of specific services and functions, which means subtracting total expense from total income and looking at the difference.

- Assessing outpatient services to the cash budget inpatient rates needed for back-room productivity.

- Establishing rates and fees based on historical expenses and income analysis for the specific service rendered, with a reasonable factor added for known overhead. 
- Determining the value of certain employees who have been hired for specific areas of expertise.

- Conducting the cost-volume-profit analysis or break-even analysis on new programs being established or traditional programs that have lost their usefulness.

If this sounds like too much trouble, welcome to the business of veterinary medicine. Every small business must look at their services and programs in this light. If you need help, or suspect that your CPA or MBA advisor has been less than helpful, call the Small Business Administration (SBA) Answer Desk, 1-800-368-5855, and ask for the nearest SCORE Chapter (Service Corp of Retired Executives). These are retired experts who volunteer their time to the SBA to help people just like you, for FREE! You may find the SCORE relationship one of the most valuable encounters you have ever attempted. You can't beat the price, so try it today! 